\title{
LITHUANIAN STOCK MARKET ANALYSIS USING A SET OF GARCH MODELS
}

\author{
Deimantė Teresienè \\ Vilnius University Kaunas Faculty of Humanities, \\ Muitinès g. 8, 44280 Kaunas, Lithuania \\ E-mail: deimante.teresiene@vukhf.lt \\ Received 19 September 2008; accepted 28 August 2009
}

\begin{abstract}
This article analyses the main factors that influence stock price volatility. The author offers a three-stage system for explaning a set of stock price volatility factors. The main point is to pay attention to investor's psychology as the main factor of price volatility. For practical analysis the returns of the OMXV index and stock prices of the Lithuanian stock market are taken and applied to a set of GARCH models. The main idea is to choose the best of the general autoregressive conditional heteroskedasticity models (GARCH) for OMXV index and all sectors. All models are ranged according to their ability to model stock price return. The main tendencies of the Lithuanian stock market are also analysed in this article by highlighting the leverage effect.
\end{abstract}

Keywords: GARCH models, index, leverage effect, stock price, volatility.

\section{Introduction}

Generalized autoregressive conditional heteroskedasticity models $(\mathrm{GARCH})$ are quite popular all over the world. These models can be used for stock, bond, indices, currency, derivative price volatility modelling and forecasting. GARCH models were applied in various areas, so the main point of the author is not to analyse the objects of the research but to find which models are the most popular.

There is not much research which analyses GARCH models in Lithuania. Girdzijauskas and Simutis (informatics) (2002), Danilenko (mathematics) (2007) applied GARCH $(1,1)$ model for financial markets. Girdzijauskas and Simutis I2002) analysed S\&P500 index's volatility so there is only one work of Danilenko (2007), in which the volatility of the OMXV index is modelled and forecasted. These researches are not carried out by economists so the main point of the articles is to present the main characteristics of the GARCH model and not the ability of modelling and forecasting volatility. Such authors as Leipus, Norvaiša (2004) and Klivečka (2007) analysed the GARCH models from a mathematical background. So there is no research in which some different GARCH type of models were applied to the Lithuanian stock market. There is a lack of such researches and economic view.

The aim of the research is: after analyzing stock price volatility factors and specifics of generalized autoregressive conditional heteroskedasticity models as a tool of volatility modelling, to create a classification system of stock price volatility factors and also practically to apply a set of "GETIP" models to the Lithuanian stock market. "GETIP" is an acronym for five GARCH type models which are applied to the OMXV index and to all corporations from the Main and Secondary lists. "GETIP" models are GARCH $(1,1)$, EGARCH $(1,1)$, TARCH $(1,1)$, IGARCH $(1,1)$ and PARCH $(1,1)$.

The tasks of the article are:

1. To inspect the reasons of stock return volatility.

2. To suggest a classification system of stock price volatility factors.

3. To apply GARCH models to the Lithuanian stock market: OMXV index and to all corporations from the Main and Secondary lists.

The object of the research is Lithuanian stock market (OMXV index and all stocks of corporations from the Main and Secondary lists). 
In this article statistical, mathematical and econometric methods are used, i.e. correlation analysis, static and dynamic prognostication, various unit root tests (ADF, PP), ARCH-LM - heteroskedasticity test, autocorrelation, partial autocorrelation, ARMA $(1,1)$, calculated "LADSH" model suitability selection criterions, various prognostication accuracy estimation parameters, applied set of general autoregressive conditional heteroskedasticity models "GETIP", descriptive statistics, regression analysis, time series. Thus, qualitative and quantitative models are used. For applying the GARCH models Eviews6 software was used.

GARCH models are widely applied for modelling the volatility of various markets, but nobody tried to apply these models to the Lithuanian stock market. In this work for the first time various GARCH models are applied to the Lithuanian stock market and the best ones are chosen for modelling and forecasting. The research is carried out using not only the OMXV index but also all the corporations from the Main and Secondary lists. Such a wide investigation of GARCH models allowed us to find the most suitable GARCH model not only for the market as a whole, but also for every company separately and for different sectors.

\section{Factors of stock return volatility}

Macroeconomic variables play a key role in asset pricing theories. For this reason, many authors have empirically studied the link between macroeconomic variables and stock market volatility. A number of studies document that a relationship exists between macroeconomic variables and equity market returns. The APT literature suggests that macroeconomic variables may proxy for pervasive risk factors (Bilson et al. 2000: 30) Both macroeconomists and finance specialists are increasing their attention to the relationship between the stock market and the rest of the economy. There can be little doubt about the growing importance of the stock market from the point of view of the aggregate economy. It has always been recognized that the stock market reflects to some extent the goings-on in the rest of the economy, but recently there has been widespread recognition that the influence is also in the opposite direction - dramatic events in the stock market are likely to have an impact upon the real economy (Black et al. 2001: 35).

Beber and Brandt (2007) in their article described a negative relation between macroeconomic uncertainty and the reduction of open interest after the news release. This result was consistent with market participants closing out hedging positions and with the degree of hedging activity depending on the degree of macroeconomic uncertainty to be hedged.

Fama and Schwert (1977) found mixed results with respect to the direction of causality between return volatility and the volatility of macroeconomic and financial variables. They found that: (a) inflation volatility predicts stock volatility and stock volatility does not predict inflation volatility, (b) money growth volatility predicts stock volatility and stock volatility predicts money growth volatility (c) industrial production volatility weakly explains the volatility of stock returns while stock volatility helps to predict industrial production volatility. Overall, their results point to a positive linkage between macroeconomic volatility and stock market volatility, with the direction of causality being stronger from the stock market to the macroeconomic variables.

Empirically, the evidence of linking macroeconomic factors to the stock market is mixed at best. Chen, Roll, and Ross (1986) were among the first to explore the link between macroeconomic variables and stock prices, and using a multifactor model they found evidence that macroeconomic factors are priced. Pearce and Roley (1985) also conclude that stock prices respond to macroeconomic news.

Bordo and Wheelock (2006) found that many, but by no means all, U.S. and British stock market crashes of the 19th and 20th centuries were followed by recessions. A serious decline in economic activity was more likely, they concluded, if a crash was accompanied or followed by a banking panic.

\subsection{Inflation's influence on stock market}

The empirical relationship between inflation and common stocks was first investigated by Jaffe and Mandelker (1976), Bodie (1976). Although employing different empirical approaches, these authors all concluded with a significant negative relationship between the proxies for inflation and stock returns. Following these pioneer studies, Fama and Schwert (1977) investigate the inflation effect on asset returns in a number of assets. They conclude that, similar to previous studies, common stocks seem to perform poorly as hedge against both expected and unexpected inflation. Since these earlier studies, the empirical literature on the Fisher Hypothesis has been prolific, and the findings have been largely similar.

The relationship between stock returns and inflation has inspired both theoretical and empirical studies. Most empirical research employed exclusively the United States (US) data in the analysis. Some papers 
extended the investigation to other country samples, but only a few employed emerging markets data.

Stocks are a good hedge against inflation because, in theory, the company's revenues and earnings should grow at the same rate as inflation over time. Of course companies can react to inflation by raising their prices, but others who compete in a global market may find it difficult to stay competitive with foreign producers who do not have to raise prices due to inflation. More importantly, inflation robs investors (and everyone else) by raising prices with no corresponding increase in value. People pay more for less. This means company's finances are overstated by inflation because the numbers (revenues and earnings) rise with the rate of inflation in addition to any added value generated by the company. When inflation declines, so do the inflated earnings and revenues.

Inflation erodes purchasing power and retirees on fixed income. That is why financial advisers caution even retirees to keep some percentage of their assets in the stock market as a hedge against inflation (Liitle 2008).

Canto and Kraussl's (2006) main results can be summarized as follows: $(i)$ there are clear short-term international dynamic interactions among the European stock futures markets; (ii) foreign economic news affects domestic returns; (iii) futures returns adjust to news immediately; (iv) announcement timing of macroeconomic news matters; $(v)$ stock market dynamic interactions do not increase at the time of the release of economic news; ( $v i$ ) foreign investors react to the content of the news itself more than to the response of the domestic market to the national news; and (vii) contemporaneous correlation between futures returns changes at the time of macroeconomic releases.

It is now taken as a stylized fact by market participants and academicians alike that returns on stocks suffer significantly in the face of high or rising inflation. This view contrasts starkly with the state of conventional wisdom and economic theory less than three decades ago, when an investment in equities was believed to be a relatively good hedge against inflation. That earlier perception was challenged by the drubbing equity investors took during the 1970s, and was refuted by several studies that offered compelling statistical evidence of inflation's negative effect on stock returns.

The other side of this coin, as some Wall Street investment strategists see it, is that the recent-years' decline in inflationary pressures and inflation expectations justifies the recent outsized stock returns, as well as the high current valuations as gauged by record-high price- earnings ratios or record-low dividend yields (Sharpe 1999).
Elaborating on Fama's work, Geske and Roll (1983) propose that, besides money demand, the money supply linkage may help explain the phenomenon. The authors propose a chain of macroeconomic events that leads to a "spurious" correlation between stock returns and inflation. They suggest that stock prices' reaction in anticipation of future economic activity (Fama's model) is highly correlated to government revenue, so that the government faces a deficit when economic output decreases. In order to balance the budget, the Treasury either borrows or issues money through the central bank, causing inflation. Thus, stock returns and inflation are negatively related due to a fiscal and monetary linkage - the Reverse Causality Hypothesis. The authors find some evidence in support of their framework, especially the signalling from stock returns to changes in nominal interest rates and changes in expected inflation.

Theoretically, inflation could be neutral with respect to stock prices. In such inflation - indexed world, news of higher-than-expected inflation is incorporated into the numerator (higher cash flows as the price increases are passed through to the consumers) of equation 1 , with an offsetting adjustment in the denominator (higher discount rates to compensate stockholders for losses in purchasing power).

$$
P_{t}=\sum_{\tau=1}^{\infty} \frac{E\left[D_{t+\tau} / \Omega_{t}\right]}{1+r_{t+\tau}} .
$$

In the first equation $P_{t}$ is the price of the stock at time $t, E\left[\cdot / \Omega_{t}\right]$ denotes the mathematical expectation conditional on information available at time $t, D_{t+\tau}$ is the dividend paid at time $t+r$, and $r_{t+\tau}$ is the stochastic risk-adjusted discount factor for cash flows that occur at time $t+r$ (Funke, Matsuda 2002). Economic announcements influence stock price movements if the new information affects either expectations of future dividends, or discount rates, or both. The new information is represented by the difference in the announced value of inflation at time $t+1$ and the expected value as of time $t$.

The historical influence of inflation on stock prices is mysterious because stocks are claims to the profits generated by the corporate capital stock, and thus they are real assets that should not be directly vulnerable to inflation (Maghayereh 2002). It is obvious that when inflation increases the $\mathrm{P} / \mathrm{E}$ ratio decreases and vice versa. Stock prices are undervalued when inflation is high, and can become overvalued when inflation drops. When examining the links between the U.S. economy and the stock market, many investment professionals rely on what is known as the "Fed model". The model 
assumes that bonds and equities compete for space in investment portfolios; if bond yields increase, then stock yields must also rise in order to remain competitive ( $\mathrm{Li}, \mathrm{Hu}$ 1998).

Historically, the rate of inflation has been a major influence on nominal bond yields. Therefore, the Fed model implies that stock yields and inflation must be highly correlated.

Christiansen and Ranaldo (2005) wrote that for bonds, the relevance of inflation and risk premium varies across the time. In the present value model, inflation (real interest rate) changes make bond and stock returns move in opposite (same) directions. Changes in risk premium and term premium typically affect bonds and stocks differently. Although the bond-stock return correlation is generally positive, the relation might be negative in periods of "flight to quality". Li, Hu (1998) shows that real interest rates drive the bond and stock comovements and that inflation shocks make bond and stock returns move in opposite directions. Other drivers that decrease the bond-stock correlation are dividends and risk premium. Moreover, he finds that the bond-stock correlation mainly depends on inflation uncertainty.

Inflation or the central bank's response to inflation damages the real economy and, by extension, the profitability of corporations. Inflation also might make investors more risk-averse, thus driving up the risk premium.

Modigliani and Cohn (1979) contend that stock investors and not their bond counterparts are subject to "inflation illusion"; that is, they fail to understand the impact of inflation on nominal dividend growth rates and extrapolate historical nominal growth rates even in periods of changing inflation. From a rational investor's viewpoint, then, stock prices are undervalued when inflation is high, and can become overvalued when inflation drops.

\subsection{Interest rates and stock market}

The tool for inflation reduction of Central bank is shortterm interest rates. By making money more expensive to borrow, the Central bank effectively removes some of the excess capital from the market. So it is essential to analyse the influence of interest rates on stock market.

The unexpected increase in inflation generates temporary variations in real and nominal interest rates. The real interest rate on loans, which affects investment decisions through the real cost of borrowing to firms, increases temporarily, generating a drop in the growth rate of investment (Dos Santos, Zezza 2004).
High energy prices, rising unit labour costs and pressure on supplies of key resources such as steel and cement guarantee that the Central bank will continue raising short-term interest rates. High interest rates and companies raising prices do not add up to an investment profile most investors enjoy.

When the next Central bank meeting is expected to bring interest rate cuts or increases, it is wise, as for a stock investor, to be aware of the potential effects behind such decisions. Although the relationship between interest rates and the stock market is fairly indirect, the two tend to move in opposite directions.

Stock valuations and interest rates are directly linked. Businesses and the stock market pay close attention to what the Central bank decides because interest rates are so important. There are obviously some very practical concerns about interest rates, such as the cost of borrowing, the effect on consumer spending and so on. There is also a fundamental consideration that this is the basis for beginning any process that leads to the valuation of a stock.

A decrease in interest rates means that those people who want to borrow enjoy an interest rate cut. But this also means that those who are lending money, or buying securities such as bonds, have a decreased opportunity to make income from interest. If we assume investors are rational, a decrease in interest rates prompts investors to move money away from the bond market to the equity market (Walti 2005). At the same time, businesses enjoy the ability to finance expansion at a cheaper rate, thereby increasing their future earnings potential, which, in turn, leads to higher stock prices. Investors and economists alike therefore view lower interest rates as catalysts for expansion.

Overall, the unifying effect of an interest rate cut is the psychological effect it has on investors and consumers; they see it as the benefit to personal and corporate borrowing, which in turn leads to greater profits and an expanding economy.

A rise in bond yields (as a result of monetary policy measures or alterations in inflation expectations), for example, will trigger a move out of stocks, as a result of which share prices and $\mathrm{P} / \mathrm{E}$ ratios fall and the earnings yield rises in parallel to the bond yield (Bulthaupt, Hofmann 2004).

A rise under the interest rates affects the valuation of the stocks. The rise in the interest rates raises the expectations of the market participants, which demand better returns commensurate with the increased returns on bonds. The above relationship of market $\mathrm{P} / \mathrm{E}$ and 10-year 
bond Yield of the US treasury gives a very good understanding of, how over the long-term the stock markets are impacted by the change in interest rates.

Moreover, under a low interest rate regime, corporates are able to increase profitability by reducing their interest expenses. However, under a rising interest rate regime since interest expenses rise, profitability is hit. Besides that, when one calculates the inherent value of a company by the cash flow discounting model, there is a twofold impact. First, there is a reduction in the cash flows due to lower profitability, second, there is a higher discounting rate due to higher interest rate regime. This leads to a relatively lower intrinsic value of the company.

Due to these reasons there may be a change in asset allocation among equities and debt. Investors, who are averse to risk, tend to move funds from one asset class to another. When interest rates rise, investors move from equities to bonds and vice versa. Having said that it does not mean that all the funds move from one asset class to another, but it happens that the marginal shift of funds does change valuations to some extent (Kim et al. 2005). Whereas interest rates drop, returns on bonds drop while the returns on equities tend to look relatively more attractive and the migration of fund from bonds to equities takes place, increasing the prices of equities.

Samitas and Kenourgios (2005) in their findings noticed that generally domestic industrial production was more prominent than domestic interest rates, while US interest rates were more prominent than US industrial production. Furthermore, a number of short run causal relationships were also found giving different implications for policy makers interested in the long run and short run contagion. The main findings strongly suggest that the emerging CE European capital markets are macroeconomically co-integrated with a German economic influence, but less or not influenced by the American global factor.
Viale (2006) wrote that the well-documented nonlinear relation between macroeconomic news and stock market returns depends on the quality of the information disclosed by what a priori investors believe to be vague news, i.e., ambiguous and noisy announcements.

\subsection{Three-dimensional system of stock volatility factors}

Factors of stock price volatility are analysed by various authors. Usually, in the literature not classified different factors in various situations are mentioned. According to the author, for the stock price volatility factors analysis a principal of "percolator"can be applied. The "percolator" principal can be explained as a classification system when all stock price volatility factors are divided into three levels, which are inside, outside factors and investors' psychology as the main factor in all the system. The author of this work thinks that investors sift all the information that they have and choose the main moments according to their psychological state, and after that they take an investment decision. So, in such a way they form supply and demand and also stock price volatility.

The explanation of stock return volatility is quite a difficult process. There is not any special formula for exact return determination. After analysing various factors of stock price volatility (according to information flows) they can be divided into inside and outside factors. All information from corporations' data sources can be assigned to the inside factors and all information, which influences stock price from corporations to the market, can be assigned to outside factors. As an additional group of factors that influence stock price can be investor's psychology. The author has noticed that there is no research about all three groups of factors together. Usually, inside and outside factors are analysed without investor's psychology and investor's psychology is analysed separately. The main idea of this three-dimensional system is shown in Fig. 1.

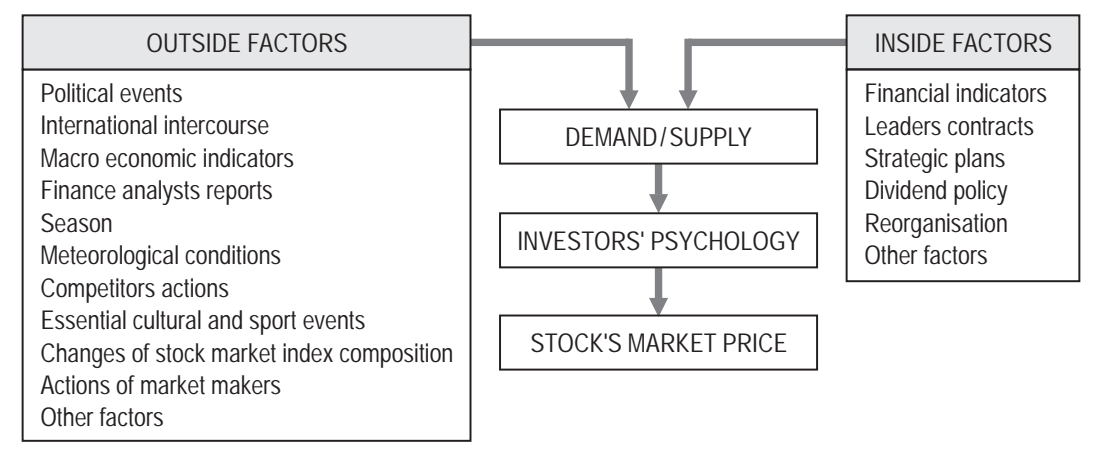

Fig. 1. Three-stage system of stock price volatility factors

Source: by author 


\section{Understanding volatility}

When we talk about asset pricing we usually use the term 'volatility'. Volatility is described as a parameter of stochastic processes that are used to model variations in financial asset prices. Two kinds of volatility can be found in the literature: implied volatility and statistical volatility (Table 1). Both of them normally refer to the same process volatility, but volatility estimates often turn out to be quite different and because volatility can only be measured in the context of a model, it is very difficult to assess the accuracy of estimates and forecasts (Alexander 2005).

Table 1. Comparison of implied and statistical volatility

\begin{tabular}{lll}
\hline & \multicolumn{1}{c}{ Implied } & \multicolumn{1}{c}{ Statistical } \\
\hline Definition & $\begin{array}{l}\text { The volatility forecast } \\
\text { over the life of an } \\
\text { option that equates } \\
\text { an observed market } \\
\text { price with the model } \\
\text { price of } \\
\text { an option. }\end{array}$ & $\begin{array}{l}\text { The volatility } \\
\text { estimate (or } \\
\text { forecast) that is } \\
\text { obtained using a } \\
\text { statistical model } \\
\text { of the real world } \\
\text { distribution of asset } \\
\text { returns. }\end{array}$ \\
\hline Data & $\begin{array}{l}\text { Risk neutral option } \\
\text { prices and investor } \\
\text { expectations. }\end{array}$ & $\begin{array}{l}\text { Historical time } \\
\text { series on underlying } \\
\text { asset prices. }\end{array}$ \\
\hline Model & $\begin{array}{l}\text { Option pricing model } \\
\text { (Black-Scholes) }\end{array}$ & $\begin{array}{l}\text { Moving averages, } \\
\text { GARCH. }\end{array}$ \\
\hline
\end{tabular}

Source: (Alexander 2005)

Volatility models can be divided into two groups: constant and time-varying volatility models.

Constant volatility models only refer to the unconditional volatility of a return process. These models have a finite constant $\sigma$, the same throughout the whole data generation process. Time-varying volatility models describe a process for the conditional volatility. The conditional distribution is a distribution that governs a return at a particular instant in time and the conditional volatility at time $t$ is the square root of the variance of the conditional distribution at time $t$.

The majority of time-varying volatility models assume that returns are normally distributed, in which case each conditional distribution is completely determined by its conditional mean and its conditional variance. The conditional mean and variance could change at every time period throughout the process, but for the purposes of estimating and forecasting conditional volatility it is often assumed that the conditional mean is a constant. (Alexander 2005).
Volatility over sufficiently long periods of time reverts back to a constant mean. However, volatility may depart from this mean for extended periods of time. This process is called "volatility clustering". Volatility clustering is one of the most important "stylized facts" in financial time series data. Whereas price changes themselves appear to be unpredictable, the magnitude of those changes. As measured, e.g. by the absolute or squared returns, it appears to be predictable in the sense that large changes tend to be followed by large changes - of either sign - and small changes tend to be followed by small changes (McQueen, Vorkink 2004).

Asset price fluctuations are thus characterized by episodes of low volatility, with small price changes, irregularly interchanged by episodes of high volatility, with large price changes. This phenomenon was first observed by Mandelbrot (1963) in commodity prices. Since the pioneering papers by Engle (1982) and Bollerslev (1986) on autoregressive conditional heteroskedastic (ARCH) models and their generalization to GARCH models, volatility clustering has been shown to be present in a wide variety of financial assets including stocks, market indices, exchange rates and interest rate securities.

Stylized facts about volatility clustering include the following:

- both good news (positive shocks) and bad news lead to higher levels of volatility;

- bad news tends to increase future volatility more than good news;

- the effect of news on volatility has a transitory (rapid decay) and more permanent (slow decay) component;

- volatility appears to have an effect on the risk premium. (McQueen, Vorkink 2004).

Volatility is a very important parameter in financial risk management. Daily volatility can be calculated using such a formula:

$$
\sigma_{\text {daily }}=\sqrt{\frac{\sum_{t=1}^{T}\left(X_{t}-\bar{X}\right)^{2}}{T-1}},
$$

where $X_{t}=100 \ln \frac{Y_{t}}{Y_{t-1}}, t=1,2, \ldots, T$. and

$$
\begin{gathered}
\bar{X}=\frac{\sum_{t=1}^{T} X_{t}}{T}, \\
\sigma_{\text {period }}=\sigma_{\text {daily }} \times \sqrt{\tau_{\text {period }}} .
\end{gathered}
$$




\section{GARCH models as volatility valuation measure}

General autoregressive conditional heteroskedasticity models (GARCH) today are the most widely used models for risk management in finance. The autoregressive conditional heteroskedasticity $(\mathrm{ARCH})$ models were introduced by Engle in 1982 and their generalization, the so-called GARCH models by Bollerslev in 1986. It has been the most commonly employed class of time series models in the recent finance literature. These models have been very successful in describing the behavior of financial return data. Their appeal comes from the fact that they can capture both volatility clustering and unconditional return distributions with heavy tails - two stylized facts associated with financial return data.

GARCH models can be applied for stock and index trading, risk management, portfolio management and asset allocation, option valuation, etc. Analysing time series it is often used for volatility clustering.

The author accomplished comprehensive research of generalized autoregressive conditional heteroskedasticity models' appliance to the Lithuanian stock market. Five heteroskedasticity models were applied to the national market: GARCH $(1,1)$, EGARCH $(1,1)$, TARCH $(1,1)$, IGARCH $(1,1)$, PARCH $(1,1)$ from which the best models are selected for each company from the Main and Secondary lists and for OMXV index. Also checked in this work is the exponential autoregressive conditional heteroskedasticity model, which was most suitable for the OMXV index, ability to forecast for short and long periods. The results of the research will help financial analysts and investors to properly value Lithuania's stock market tendencies and replenish a set of market analysis tools in Lithuania's conditions. The estimation of the GARCH model involves the joint estimation of a mean and a conditional variance equation (Lildholdt 2002).

In the standard GARCH $(1,1)$ specification:

$$
\sigma_{t}^{2}=\omega+\alpha \varepsilon_{t-1}^{2}+\beta \sigma_{t-1}^{2},
$$

$\sigma_{t}^{2}$ is the one-period ahead forecast variance based on past information, it is called the conditional variance. The conditional variance equation specified in formula (5) is a function of three terms:

- The mean: $\omega$.

- News about volatility from the previous period, measured as the lag of the squared residual from the mean equation: $\varepsilon_{t-1}^{2}$ (the $\mathrm{ARCH}$ term).

- Last period's forecast variance: $\sigma_{t-1}^{2}$ (the GARCH term).
Nelson (1991) created the model which values the leverage effect and called such a model exponential GARCH (EGARCH). Nelson argued that the nonnegativity constraints in the linear GARCH model were too restrictive. The GARCH model imposes the non-negative constraints on the parameters $\alpha_{i}$ and $\gamma_{j}$, while there are no restrictions on these parameters in the EGARCH model. In the EGARCH model, the conditional variance, $\sigma_{t}$ is an asymmetric function of lagged disturbances $u_{t-i}$ :

$$
\log \left(\sigma_{t}^{2}\right)=\alpha_{0}+\alpha_{1}\left|\frac{u_{t-1}}{\sigma_{t-1}}\right|+\beta_{1} \log \left(\sigma_{t-1}^{2}\right)+\gamma \frac{u_{t-1}}{\sigma_{t-1}} .
$$

The other model which analyses the leverage effect of new information on stock volatility is TARCH. This model was analysed by such authors as Zakoian (1994) and Glosten et al. (1993). This model can be explained as follows:

$$
\begin{gathered}
\sigma_{t}^{2}=\omega+\sum_{j=1}^{p} \beta_{j} \sigma_{t-j}^{2}+\sum_{i=1}^{q} \alpha_{i} u_{t-i}^{2}+\sum_{k=1}^{r} \gamma_{k} u_{t-k}^{2} I_{t-k}^{-}, \\
I_{t-k}^{-}=\left\{\begin{array}{c}
1 \text { if } u_{t}<0 \\
0 \text { otherwise. }
\end{array}\right.
\end{gathered}
$$

In this model "good news" $u_{t-i}>0$ and "bad news" $u_{t-i}<0$, have different influence on conditional variance. When $\gamma_{k}=0$ for all $k$, then the TARCH model is adequate for the GARCH model. The difference between TARCH and EGARCH is that in the first model leverage effect has expression of quadratic and in the other one - exponential. In TARCH and EGARCH models persistence of volatility is very long.

When $\alpha+\beta=1$ and $\beta=\lambda$, the main GARCH expression can be rewritten as follows:

$$
\sigma_{t}^{2}=\omega+(1-\lambda) \varepsilon_{t-1}^{2}+\lambda \sigma_{t-1}^{2}, 0 \leq \lambda \leq 1 .
$$

There is no defined non-conditional variance and time forecasts do not converge in this model. So, in this situation the process of variance is not stationary, therefore such a model is called integrated GARCH (IGARCH). Most GARCH models analyse conditional variance. Analysing volatility researches often have a mean standard deviation. But some researches offered GARCH model which uses standard deviation. Such class of models was defined by Ding, Granger (1996) and this idea was named power ARCH model (PARCH). This model can be expressed in such a way:

$$
\sigma_{t}^{\delta}=\omega+\sum_{j=1}^{p} \beta_{j} \sigma_{t-j}^{\delta}+\sum_{i=1}^{q} \alpha_{i}\left(\left|u_{t-i}\right|-\gamma_{i} u_{t-i}\right)^{\delta},
$$

where $\delta>0,\left|\gamma_{i}\right| \leq 1$, when $i=1,2, \ldots, r$ and $\gamma_{i}=0$, when $i>r$ and $r \leq p$. 
PARCH model when $\gamma \neq 0$ has a leverage effect. PARCH model can be explained as GARCH when $\delta=$ 2 and $\gamma_{i}=0$ for every $i$.

When two or more models are taken for analysis which have the same number of the parameters, then for suitability selection log likehood function can be used. But when the models have a different number of parameters, Akaike information criterion is used. If the number of model parameters is signed P, then AIC can be expressed as follows:

$$
\operatorname{AIC}(P)=2 \ln (\text { maximum likelihood })-2 \mathrm{P} .
$$

\section{The practice of a set of ,GETIP“6 models in the Lithuanian stock market}

"GETIP" is an acronym of five GARCH type models which are applied to OMXV index and to all corporations from the Main and Secondary lists. "GETIP" models are GARCH $(1,1)$, EGARCH $(1,1)$, TARCH $(1,1)$, IGARCH $(1,1)$ and PARCH $(1,1)$. The period for analysis is from 2000-01-01 till 2008-01-18. All the results of the research are shown in Table 2.

Estimated "GETIP" models' coefficients:

\section{- GARCH}

$$
\sigma^{2}=1.59 E-05+0.156801 \varepsilon_{t-1}^{2}+0.606602 \sigma_{t-1}^{2} \text {. }
$$

- EGARCH

$$
\begin{array}{r}
\log \left(\sigma_{t}^{2}\right)=-0.169412+0.987085 \log \sigma_{t-j}^{2}+ \\
0.068175\left|\frac{\varepsilon_{t-i}}{\sigma_{t-i}}\right|-0.002287 \frac{\varepsilon_{t-k}}{\sigma_{t-k}} .
\end{array}
$$

\section{- TARCH}

$$
\begin{aligned}
\sigma_{t}^{2}= & 1.46 E-05+0.619615 \sigma_{t-j}^{2}+0.120691 \varepsilon_{t-i}^{2}- \\
& 0.083507 \varepsilon_{t-k}^{2} I_{t-k} .
\end{aligned}
$$

\section{- IGARCH}

$\sigma_{t}^{2}=0.975629 \sigma_{t-j}^{2}+0.024371 \varepsilon_{t-i}^{2}$.

- PARCH

$$
\begin{aligned}
\sigma_{t}^{1}= & 9.79 E-05+0.964464 \sigma_{t-j}^{1}+ \\
& 0.035655\left(\left|\varepsilon_{t-i}\right|-0.053604 \varepsilon_{t-i}\right)^{1} .
\end{aligned}
$$

According to the author the models can be ranged as follows:
1. EGARCH
2. PARCH
3. TGARCH
4. GARCH
5. IGARCH

A set of GARCH models was applied to all sectors classified by GICS. The results of suitability of different GARCH models for separate sectors are shown in Figures 2-5.

For those investors who use general autoregressive conditional heteroskedasticity models the author of this article offers to use different models for separate sectors:

- OMXV index - EGARCH;

- Health Care - PARCH;

- Energy - TARCH;

- Materials - LFO - EGARCH; GRG - GARCH;

- Industrials - EGARCH;

- Consumer Discretionary - VBL, KBL - PARCH, SNG, APG - TARCH, UTR, LNS - GARCH;

- Consumer Staples - EGARCH;

- Financial - TARCH;

- Telecommunication Services - PARCH;

- Utilities - EGARCH.

Table 2. Suitability of "GETIP" models for OMXV index

\begin{tabular}{rccccc}
\hline & GARCH & EGARCH & TGARCH & IGARCH & PARCH \\
\hline$\alpha$ & 0.156801 & 0.068175 & 0.120691 & 0.024371 & 0.035655 \\
\hline$\beta$ & 0.606602 & 0.987085 & 0.619615 & 0.975629 & 0.964464 \\
\hline$\omega$ & $1.59 \mathrm{E}-05$ & -0.169412 & $1.46 \mathrm{E}-05$ & $9.79 \mathrm{E}-05$ \\
\hline$\gamma$ & & -0.002287 & 0.083507 & 0.053604 \\
\hline LL & 7938.516 & 7954.939 & 7942.262 & 7911.981 & 7954.289 \\
\hline AIC & -6.922788 & -6.936247 & -6.92518 & -6.901380 & -6.935679 \\
\hline Durbin-Watson stat & 1.804854 & 1.808738 & 1.808568 & 1.811963 & 1.808517 \\
\hline Schwarz criterion & -6.910273 & -6.921228 & -6.91016 & -6.893870 & -6.920661 \\
\hline Suitability according to AIC & 4 & -6.930770 & -6.91970 & -6.898641 & -6.930203 \\
\hline
\end{tabular}




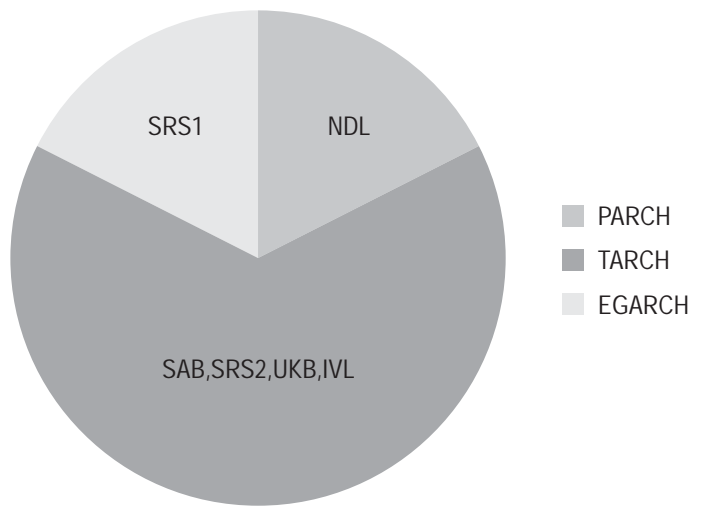

Fig. 2. Financial sector

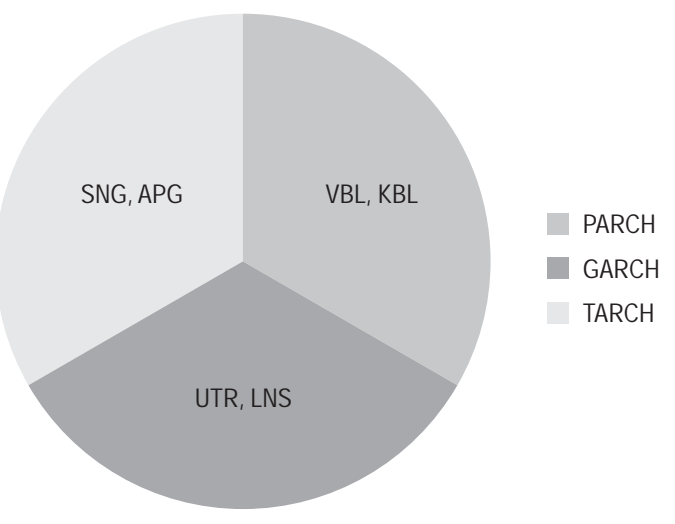

Fig. 4. Consumer Discretionary

The best GARCH model for the Lithuanian stock market is EGARCH (for OMXV index and most sectors), so it is important to analyse the ability to forecast by this model. In Table 3 the relationship between forecast measures and time horizon is placed using exponential GARCH model.

After analysing EGARCH model's abilities to forecast in different periods, the conclusion can be drawn that there is not any tendency for which time horizon this model forecast is the best (Fig. 6). At a first glance it can appear that in short time $(5,10$ days $)$ EGARCH

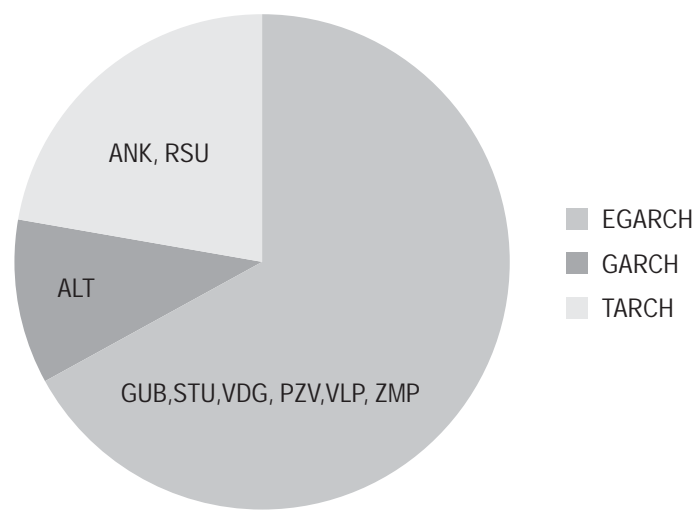

Fig. 3. Consumer Staples

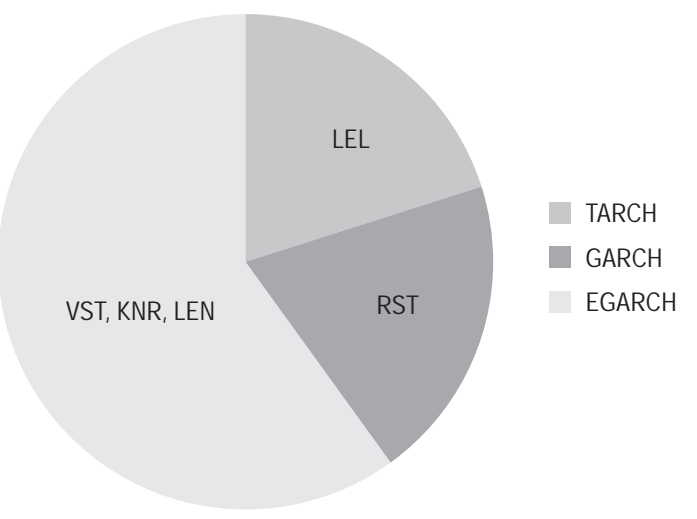

Fig. 5. Utilities

model forecasts better than in long period, but the correlation coefficient is only 0.24 which is not significant. After doing the research, the conclusions can be made that for the Lithuanian stock market the most suitable model is EGARCH. This model has a strong leverage effect which means that bad news has more effect on stock price volatility than good news. Thus, according to such an idea all investors tend to remember bad events longer than good information. Therefore, according to the author when bad information appears in the stock market it is quite difficult to value the flows of positive information.

Table 3. A relationship between forecast measures and time horizon

\begin{tabular}{lccccccccc}
\hline & 5 & 10 & 20 & 40 & 50 & 100 & 150 & 200 & 255 \\
\hline RMSE & 0.003929 & 0.004051 & 0.005551 & 0.006659 & 0.010110 & 0.008294 & 0.008380 & 0.008541 & 0.009324 \\
\hline MAE & 0.003271 & 0.003539 & 0.004621 & 0.005287 & 0.007317 & 0.005953 & 0.006196 & 0.006220 & 0.006703 \\
\hline MAPE & 54.69204 & 101.9385 & 113.0571 & 108.6843 & 105.4331 & 107.9143 & 103.9420 & 102.1564 & 101.8848 \\
\hline TIC & 0.467739 & 0.559675 & 0.688790 & 0.780713 & 0.861805 & 0.871881 & 0.890858 & 0.905589 & 0.922204 \\
\hline BP & 0.492965 & 0.007013 & 0.001774 & 0.028096 & 0.032032 & 0.016650 & 0.000021 & 0.000807 & 0.003409 \\
\hline VP & 0.479679 & 0.947198 & 0.930804 & 0.886159 & 0.895631 & 0.844829 & 0.837958 & 0.843370 & 0.869464 \\
\hline CP & 0.027356 & 0.045789 & 0.067422 & 0.085745 & 0.072336 & 0.138521 & 0.162021 & 0.155823 & 0.127127 \\
\hline
\end{tabular}




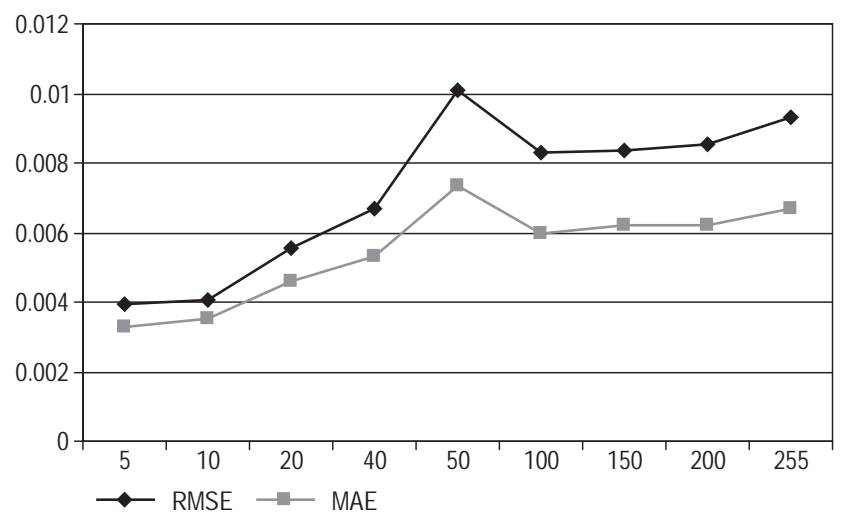

Fig. 6. RMSE and MAE dynamics over the forecast period

\section{Conclusions}

1. Analysing generalized autoregressive conditional heteroskedasticity models the author excludes the three main characteristics. That is, the principal of heteroskedasticity, volatility clusterization (including excess, asymmetry and Jarque-Bera test) and also leverage effect. The origin of the heteroskedasticity idea in finance gave bigger opportunities for investors in forecasting stock price volatility. In homoskedastic processes when the variance is determined and static, such a way is not suitable because the results of research would be wrong. For more accurate return forecasts volatility clusterization should be estimated. Analysing stock price dynamics volatility clusters can usually be noticed, which periodically repeats. According to the author there is a direct dependence between information flows and volatility clusters. It is important to underline that the influence of information on stock price volatility depends on its type (bad or good news) though clusters form in both situations. The other essential characteristics of heteroskedasticity models is a leverage effect when bad news has bigger impact on stock price than good news.

2. After the investigation of various GARCH models, all of them can be classified into univariate and multivariate models. Because of the big variety of GARCH models, a problem of suitable model selection appears. For this purpose it is essential to use model selection criterions which help to value the level of model suitability. There are various types of model selection criterions but not all of them are suitable for different situations, others are very similar and give the same results. According to the author's empirical researches the best results were achieved using Akaike in- formation criterion. Using "LADSH" - a set of model selection criterions the author noticed that only in some situations the results of range were different.

3. The research of the Lithuanian stock market showed that the market is stationary and the data is not distributed normally. GARCH type of models can be applied to the Lithuanian stock market because for analysed returns homoskedasticity is not suitable. After using a set "GETIP" of GARCH models, the author noticed that the most suitable model for OMXV index is EGARCH. From the research results the conclusion can be drawn that there is a leverage effect in the Lithuanian stock market. So this means that investors react more to bad news than to good news. In this way the situation of nowadays in stock market can be explained. Moreover, bad news from USA and Europe dwarfed good news about separate corporation financial data. According to model selection results the hypothesis can be rejected that the best model for the Lithuanian security market is GARCH $(1,1)$.

4. After the application of GETIP- a set of GARCH models, to all sectors of the Lithuanian stock market some tendencies can be excluded. Exponential generalized autoregressive conditional heteroskedasticity model (EGARCH) is the most suitable for industrials, consumer staples, information technology and utilities sectors. TARCH is the best for the energy and finance sectors. A power generalized autoregressive conditional heteroskedasticity model (PARCH) is best reflected in health care and telecommunication services sectors. Consumer discretionary sector did not distinguish any tendencies because three models PARCH, GARCH and TARCH gave the same results. According to the author it is quite difficult to forecast the volatility of this sector and herewith there is a risk to invest in it. For the materials sector the most suitable are GARCH(GRG) and EGARCH(LFO) models.

5. The researches of volatility forecasting using EGARCH model should be used for static forecast method because of more accurate prognosis. Analysing various statistical methods of forecasting accuracy it has been noticed that there is not a significant relationship between EGARCH model accuracy and the period of forecast. The correlation coefficient between the mentioned parameters is 0.237781 which rejects the strong dependence. 


\section{References}

Alexander, C. 2005. Market Models: A Guide to Financial Data Analysis. England. 400 p.

Beber, A.; Brandt, M. W. 2007. Resolving Macroeconomic Uncertainty in Stock and Bond Markets. University of Lausanne.

Bilson, Ch.; Brailsford, T.; Hooper, V. 2000. Selecting Macroeconomic Variables as Explanatory Factors of Emerging Stock Market Returns. Department of Commerce Australian National University. Canberra, Australia.

Black, A.; Fraser, P.; Groenevold, N. 2001. US Stock Prices and Macroeconomic Fundamentals. Aberdeen Papers in Accountancy, Finance \& Management. Working Paper No. 01-3.

Bodie, Z. 1976. Common stocks as a hedge against inflation, Journal of Finance 31: 459-470. doi:10.2307/2326617

Bollerslev, T. 1986. Generalised autoregressive conditional heteroskedasticity, Journal of Econometrics 31: 307-27. doi:10.1016/0304-4076(86)90063-1

Bordo, M. D.; Wheelock, D. C. 2006. When Do Stock Market Booms Occur? The Macroeconomic and Policy Environments of 20th Century Booms. Federal reserve bank of St. Louis.

Bulthaupt, F.; Hofmann, Th. 2004. A macroeconomic stock market model, Journal of Economy \& Markets: 1: 24-32.

Canto, B.; Kräussl, R. 2006. Stock Market Interactions and the Impact of Macroeconomic News - Evidence from High Frequency Data of European Futures Markets. Free University of Amsterdam and Center for Financial Studies. Frankfurt.

Chen, F.; Roll, R.; Ross, S. 1986. Economic forces and the stock market, Journal of Business 59(3): 383-403. doi:10.1086/296344

Christiansen, Ch.; Ranaldo, A. 2005. Realized Bond-Stock Correlation: Macroeconomic Announcement Effects. Finance Research Group. Aarhus School of Business.

Danilenko, S. 2007. Mathematical models appliance to stock market analysis, Lithuanian Mathematical Journal 47: 442-447.

Ding, Z.; Granger, C. 1996. Modeling volatility persistence of speculative returns: A new approach, Journal of Econometrics 73(1): 185-215. doi:10.1016/0304-4076(95)01737-2

Dos Santos, C.H.; Zezza, Z. 2004. A Post-Keynesian Stockflow Consistent Macroeconomic Growth Model: Preliminary Results. The Levy Economics Institute.

Engle, R. F. 1982. Autoregressive conditional heteroskedasticity with estimates of the variance of UK inflation, Econometrica 50: 987-1007. doi:10.2307/1912773

Fama, E. F.; Schwert, G. W. 1977. Asset returns and inflation, Journal of Financial Economics 5: 115-146. doi:10.1016/0304-405X(77)90014-9
Funke, N.; Matsuda, A. 2002. Macroeconomic News and Stock Returns in the United States and Germany. IMF Working Paper.

Geske, R.; Roll, R. 1983. The fiscal and monetary linkage between stock returns and inflation, Journal of Finance 38: 1-33. doi: $10.2307 / 2327635$

Girdzijauskas, Š.; Simutis, R. 2002. Stock market indexes forecasting possibilities using GARCH $(1,1)$ model, in Conference Papers in Informatics. Kaunas: Technologija, 326-330.

Glosten, L. R.; Jagannathan, R.; Runkle, D. E. 1993. On the relation between the expected value and the volatility of the nominal excess returns on stocks, Journal of Finance 48(5): 1779-1791. doi:10.2307/2329067

Jaffe, J. F.; Mandelker, G. 1976. The "Fisher Effect" for risky assets: an empirical investigation, Journal of Finance 31(2): 447-458. doi:10.2307/2326616

Kim, S. J.; McKenzie, M. D.; Faff, R. W. 2004. Macroeconomic news announcements and the role of expectations: evidence for US bond, stock and foreign exchange markets, Journal of Multinational Financial Management 14(4): 217-232. doi:10.1016/j.mulfin.2003.02.001

Klivečka, A. 2007. GARCH $(1,1)$ process can have arbitrarily heavy power tails, Lithuanian Mathematical Journal 47(2): 196-210.

Leipus, R.; Norvaiša, R. 2004. Financial markets theories appliance, Money Studies 1: 31-53.

Li, L.; Hu, Z. F. 1998. Responses of the Stock Market to Macroeconomic Announcements Across Economic States. IMF Working Paper. IMF Institute.

Liitle, K. 2008. What Stock Investors Should Know About Inflation. Available from Internet: $<$ http://stocks.about.com/ od/marketnews/a/Inflat101105.htm>.

Lildholdt, P. M. 2002. Estimation of GARCH Models Based on open, close, high, and low Prices, University of Aarhus, Aarhus School of Business.

Maghayereh, A. 2002. Causal Relations Among Stock Prices and Macroeconomic Variables in the small, open Economy of Jordan. The Hashemite University, Jordan.

Mandelbrot, B. 1963. The variation of certain speculative prices, Journal of Business 36: 394-419. doi:10.1086/294632

Mcqueen, Grant; Vorkink, Keith. 2004. Whence GARCH? A Preference-Based Explanation for Conditional Volatility, Brigham Young university.

Modigliani Franco; Richard A. Cohn. 1979. Inflation, rational valuation and the market, Financial Analysts Journal 35(2): 24-44. doi:10.2469/faj.v35.n2.24

Nelson, D. B. 1991. Conditional heteroscedasticity in asset returns: a new approach, Econometrica 55: 703-708.

Pearce, D. K.; Roley, V. V. 1985. Stock prices and economic news, Journal of Business 58(1): 49-69. doi:10.1086/296282 
Samitas, A. G.; Kenourgios, D. F. 2005. Macroeconomic factors' influence on "new" European countries stock returns: the case of four transition economies, International Journal of Financial Services Management 2(1): 4-20.

Sharpe, S. A. 1999. Stock Prices, Expected Returns, and Inflation. Division of Research and Statistics. Federal Reserve Board. Washington.

Viale, A. M. 2006. Testing Overreaction and Underreaction to Macroeconomic News: The Role of Noisy and Ambiguous Signals in the Stock Market. Texas A \& M University, College Station. 42 p.

Walti, S. 2005. The Macroeconomic Determinants of Stock Market Synchronization. Dublin: Trinity College.

Zakoian, J.-M. 1994. Threshold heteroskedastic models, Journal of Economic Dynamics and Control 18: 931-955. doi:10.1016/0165-1889(94)90039-6 